Original scientific paper

\title{
Digital Technology as a Tool in Self-management of Painful Low Back Syndrome
}

\author{
Mirjana Berković-Šubić \\ Health Centre in Zagreb County \\ Gajeva 37, Samobor, Croatia \\ mirjana.berkovic@gmail.com \\ Gilbert Hofmann \\ Health Resort Veli Lošinj \\ Podjavori 27, Veli Lošinj, Croatia \\ gilbert@net.hr \\ Biserka Vuzem \\ Special Hospital for Medical Rehabilitation Krapinske Toplice \\ Gajeva 2, Krapinske Toplice, Croatia \\ biba.vuzem@gmail.com
}

\section{Summary}

The development of electronic media has enabled the health service users an open access to different medical information. The patients are not satisfied only with the medical report and diagnosis made by a professional, they want to know more. Therefore digital technology is used to gain more information about the painful syndromes in the lower back. This process can be called e-low back pain. The pain that occurs in the lower back is called lumbago and it can have several causes. The aim of this paper is to analyze the lumbago patients' active participation in order to achieve new knowledge and to expand the already existing ones using different internet sources. The hypothesis stated in the research: H1: Participants show interest and positive attitude in using information technology in order to assist in the back pain treatment. This research carried out the result analysis of the E-back pain questionnaire about the usage of information technology and the digital communication capabilities in order to achieve new knowledge and to expand the already existing one related to the back pain. 120 participants responded to the research, dominantly middle-aged (average age 49.25 years). In conclusion, participants express their positive opinion about using modern information technologies in acquiring and expanding their knowledge about the back pain.

Key words: lumbago, back pain, electronic media, e-back pain, open access, the Internet 
INFuture2017: Integrating ICT in Society

\section{Introduction}

The development of information and communication technology has caused radical changes in new knowledge acquisition which has become easily accessible to interested individuals.

When technology like computers, internet, and multimedia devices are included in the learning process, we can call it e-learning. Easily accessible contents on Internet enable the progress in upgrading and expanding the existing cognition. In fast-growing economies profit plays the most important role and the employees are forced to work even if they have musculoskeletal problems and they cannot exercise their right to get a granted medical leave because of pain. In the last decades the number of back pain patients has increased. (Deyo et al, 2014). Chronic back pain treatment is one of the most common reasons for visiting a physician or a physiotherapist (Lin et al, 2011),

In modern society many new professions have emerged and the employees' standing or sitting position is required throughout the whole working hours which often results with the low back pain (LBP). The consequence of a longterm sitting or standing position is the improper load of musculoskeletal system. Therefore some muscles are overloaded while the others weaken due to inactivity. If the improper body positions last longer and are repeated on a long term basis, the result is a chronic, painful condition. The back pain lasting longer than twelve weeks is called chronic lumbago (American Pain Society, 2007). Lifelong back pain prevalence is up to $80 \%$ (Smith et al, 2014).

In order to change their painful condition, the patients visit a physician to set a correct diagnosis and to determine the cause of pain. Patients often use e-media to expand their knowledge and also to find information about some therapeutic exercises they could practice in a home environment to treat the back pain and by doing that, they take part in forming the concept of e-back pain. In the past the information about health care was quite unavailable to patients and they could be given some only in direct contact with a particular medical practitioner. Nowadays the availability of all kinds of medical educational content has enormously increased due to the broad media support.

In the process of physiotherapy, patients are active participants, so the physiotherapist gives them advice how to overcome the daily activities, perform exercises, and the adaptation at work. Due to inability to get a granted leave, a person with back pain practices learned exercises at home on a daily basis to improve their painful condition. There are many people who do not have medical education but want to know more about their illness and its outcomes. The most widely used media is the Internet that offers countless opportunities. The Internet is a global data network that is publicly available and offers various services (Croatian declaration on open access, 2012).

Internet technology offers a wide range of solutions to acquire and improve the already existing knowledge. For example, the social networks like Facebook, as the most accessible one, publishes a large amount of visual and textual material 
M. Berković-Šubić, G. Hofmann, B. Vuzem, Digital technology as a tool in self-management ...

from different Internet portals, and the readers can choose the content according to their interests or medical difficulties.

Since the back pain is a serious medical condition, its treatment should be approached according to the recommendations of the world and national guidelines for the low back pain treatment (Grazio et al, 2012)

The aim of this research is to determine how much the respondents use the electronic media in order to expand their knowledge about the back pain and to assist in the chronic back pain treatment.

Hypothesis H1: The participants show interest and positive attitude in using the electronic media in order to assist in the back pain treatment.

\section{Materials and methods}

Participants for this study $(\mathrm{N}=120)$ were randomly selected from a group of low back pain treated patients at Special Hospital for Medical Rehabilitation Krapinske Toplice.

The approval for conducting this research was obtained by the Special Hospital for Medical Rehabilitation Krapinske Toplice Ethical Committee and with the consent of the hospital director.

The fundamental ethical integrity of the respondents was also respected and no data abuse used for other purposes.

The research was carried out in the period from January to April 2017, by anonymous, a specially constructed questionnaire with 10 questions for the research purposes created by the author.

By completing the survey, each respondent was familiar with the reason and research protocol confirmed their participation with signature. The questionnaire contained besides demographic questions also questions related to the use of electronic media and Internet capabilities in purpose of assisting in the back pain treatment. The questions were formulated with the ability to respond to Likart's scale (5 answers). The results are statistically processed and expressed as average values, the differences were compared by variance analysis, and statistical significance was determined as $\mathrm{p}<0.05$.

The comparison of average attitude values in relation to age, gender and degree of education was made.

\section{Results}

This research describes the participants' interest and attitudes regarding the use of modern technologies to assist in the chronic back pain treatment. Among 120 participants $(\mathrm{N}=120)$ there were $55 \%$ women and $45 \%$ men, average age 49.25 . The participants aged from 25 to 77 were divided into four age groups:

- group aged less than 40

- group aged from 41-50

- group aged from 51-60

- group aged more than 60 . 
The majority of the participants were in the age group of 51 to 60 years of age, $33.3 \%(\mathrm{~N} 40)$, and the least of them $16.7 \%(\mathrm{~N} 20)$ were in the age group over 60 years (Table 1).

Table 1. Presentation of the respondents by gender and age

\begin{tabular}{|l|c|c|c|c|c|c|}
\hline \multirow{2}{*}{ Respondents } & \multicolumn{3}{|c|}{ Gender } & \multicolumn{4}{c|}{ Age (Grades in years) } \\
\cline { 2 - 7 } & M & F & $<\mathbf{4 0}$ & $\mathbf{4 1 - 5 0}$ & $\mathbf{5 1 - 6 0}$ & $>\mathbf{6 0}$ \\
\hline Number & 54 & 66 & 29 & 31 & 40 & 20 \\
\hline Percentage (\%) & $45 \%$ & $55 \%$ & $24.2 \%$ & $25.8 \%$ & $33.3 \%$ & $16.7 \%$ \\
\hline Total (N) & \multicolumn{2}{|c|}{120} & \multicolumn{4}{c|}{120} \\
\hline
\end{tabular}

\section{Presentation of the demographic characteristics of the respondents}

According to the education level, the majority of the respondents belong to a group of unskilled or qualified workers, $50 \%, 31.66 \%$ of secondary education respondents and $16.33 \%$ of the respondents have college or university degree.

Table 2. Presentation of the respondents according to their qualifications in relation to the age group

\begin{tabular}{|c|c|c|c|c|c|}
\hline \multirow[b]{2}{*}{ Age } & \multicolumn{3}{|c|}{ Qualifications } & \multirow[b]{2}{*}{ Total } & \multirow[b]{2}{*}{$\%$} \\
\hline & $\begin{array}{c}\text { unskilled/ } \\
\text { vocational education }\end{array}$ & high school & $\begin{array}{c}\text { college/ } \\
\text { university degree }\end{array}$ & & \\
\hline$<40$ & 17 & 8 & 4 & 29 & $24.0 \%$ \\
\hline $41-50$ & 13 & 12 & 6 & 31 & $26.0 \%$ \\
\hline $51-60$ & 18 & 14 & 8 & 40 & $33.3 \%$ \\
\hline$>60$ & 12 & 4 & 4 & 20 & $16.7 \%$ \\
\hline Total & 60 & 38 & 22 & 120 & $100.0 \%$ \\
\hline
\end{tabular}

\section{Distribution of frequency response by individual statement}

In statement T1: The use of modern information technologies (Internet, social networks) helps me in gaining and expanding knowledge about back pain; 93 respondents expressed positive attitude, 20 neutral and 7 of them negative attitude.

In statement T2: Available tips in the form of a movie or a back pain image are useful; 102 of the respondents expressed positive attitude, 15 neutral and 3 negative attitude.

In statement T3: My physiotherapist's information on the possibilities of using information technology to meet my illness was useful; 95 respondents expressed positive attitude, 17 neutral and 8 expressed negative attitude.

In statement T4: The most information about the back pain I got by using the Internet; 28 respondents expressed positive attitude, 18 neutral and 74 negative attitude.

In statement T5: I use tips from scientific biomedical databases to treat my back pain; 43 respondents expressed positive attitude, 31 neutral and 46 negative attitude. 
M. Berković-Šubić, G. Hofmann, B. Vuzem, Digital technology as a tool in self-management ...

In statement T6: The Internet useful to me as a reminder to carry out previously learned back pain treatment exercises; 82 respondents expressed positive attitude, 17 neutral and 21 negative attitude.

In statement T7: I do not dare to use Internet and social networking self-help back pain tips; 55 respondents expressed positive attitude, 25 neutral and 40 negative attitude.

In statement T8: The lack of skill for modern information technologies (Internet, social networks) is a problem for me in acquiring new knowledge about my health; 31 respondents expressed positive attitude, 17 neutral and 72 negative attitude.

In statement T9: No knowledge of English is a problem for me to acquire new information about back pain; 51 respondents expressed positive attitude, 10 neutral and 59 negative attitude.

In statement T 10: I cannot do the back pain treatment without a specialist; 108 respondents expressed positive attitude, 3 neutral and 9 negative attitude.

All the asserted claims were handled individually and express the respondents' attitudes about the modern technology for the purpose of finding useful tips for the back pain treatment and the obtained results are expressed as average results (Table 3 and Table 4).

Table 3. Presentation of the results of the individual statements and the respondents' attitudes about the usefulness of information on the Internet about the back pain in relation to the age

\begin{tabular}{|l|c|c|c|c|c|c|}
\hline \multirow{2}{*}{} & \multicolumn{4}{|c|}{ Age (grades in years) } & \multicolumn{2}{c|}{ Anova } \\
\cline { 2 - 5 } & $\mathbf{4 4 0}$ & $\mathbf{4 1 - 5 0}$ & $\mathbf{5 1 - 6 0}$ & $\mathbf{> 6 0}$ & \multicolumn{2}{|c|}{ Sig. } \\
\hline Statements & $\mathrm{M}$ & $\mathrm{M}$ & $\mathrm{M}$ & $\mathrm{M}$ & $\mathrm{F}$ & Sig. \\
\hline S1 & 3.76 & 4.13 & 4.08 & 3.35 & 5.712 & 0.001 \\
\hline S2 & 3.90 & 4.26 & 4.03 & 3.60 & 4.639 & 0.004 \\
\hline S3 & 3.86 & 3.97 & 4.13 & 3.60 & 1.711 & 1.69 \\
\hline S4 & 2.55 & 2.77 & 2.58 & 1.90 & 3.512 & 0.018 \\
\hline S5 & 2.52 & 3.29 & 3.10 & 2.25 & 6.138 & 0.001 \\
\hline S6 & 3.55 & 3.87 & 3.60 & 3.05 & 3.156 & 0.027 \\
\hline S7 & 3.28 & 2.90 & 3.13 & 3.65 & 2.319 & 0.079 \\
\hline S8 & 2.28 & 2.77 & 2.30 & 2.95 & 2.860 & 0.040 \\
\hline S9 & 2.24 & 2.90 & 2.85 & 3.70 & 7.014 & 0.000 \\
\hline S10 & 2.24 & 4.13 & 4.13 & 4.50 & 1.009 & 0.391 \\
\hline N & 29 & 31 & 40 & 20 & 120 & \\
\hline
\end{tabular}

Overall looking at the results obtained, it is evident that the positive attitude of the respondents over the use of modern technologies prevails for the purpose of the assisting in the back pain treatment.

Men express slightly more positive attitudes than women, but there was no statistically significant difference in the views of these two groups. By comparing different age groups in attitudes towards the use of modern technologies for the purpose of the assisting in the low back pain treatment, it is evident that positive 
attitudes are expressed by respondents aged 41-50 and 51-60, and with the age increase (more than 60 years) this positive trend decreases. Compared to the age, a statistically significant difference in positivity was confirmed in relation to the statements. $\mathrm{S} 1=\mathrm{p}<0.001, \mathrm{~S} 2=\mathrm{p}<0.004, \mathrm{~S} 4=\mathrm{p}<0.018, \mathrm{~S} 5=\mathrm{p}<0.001$, $\mathrm{S} 6=\mathrm{p}<0.027$ i $\mathrm{S} 8=\mathrm{p}<0.040$. A slightly lower attitude was found in the youngest age group ( $<$ from 40 years), however, in this group most of the respondents are with lower qualifications who are exposed to heavier physical activity (and the problems with back pain), as well as fewer opportunities to use information technology at the workplace, therefore a lower inclination to the same. The correlation between occupation and professional background and attitudes about the usefulness of Internet information about the low back pain shows a statistically significant difference in the claims $\mathrm{S} 8=\mathrm{p}<0.032$ i $\mathrm{S} 9=\mathrm{p}<0.017$, where the possible reasons mentioned is the ignorance of the use of the information technology and the foreign language (English).

Table 4: Presentation of the results of the individual statements and the respondents' attitudes about the usefulness of information on the Internet about the back pain in relation to the level of education

\begin{tabular}{|l|c|c|c|c|c|}
\hline \multirow{2}{*}{} & \multicolumn{3}{|c|}{ Level of education } & \multicolumn{2}{c|}{ Anova } \\
\cline { 2 - 4 } & $\begin{array}{c}\text { unskilled } \\
\text { vocational }\end{array}$ & $\begin{array}{c}\text { High } \\
\text { school }\end{array}$ & Coll. Univ & \multicolumn{2}{c|}{} \\
\hline Statements & M & M & M & F & Sig. \\
\hline S1 & 3.80 & 3.92 & 4.09 & 1.143 & 0.322 \\
\hline S2 & 3.88 & 4.08 & 4.09 & 1.385 & 0.254 \\
\hline S3 & 3.92 & 3.92 & 4.00 & 0.077 & 0.926 \\
\hline S4 & 2.43 & 2.61 & 2.55 & 0.362 & 0.697 \\
\hline S5 & 2.75 & 3.05 & 2.86 & 0.918 & 0.402 \\
\hline S6 & 3.53 & 3.58 & 3.64 & 0.096 & 0.909 \\
\hline S7 & 3.22 & 3.32 & 2.91 & 1.121 & 0.330 \\
\hline S8 & 2.73 & 2.47 & 2.05 & 3.544 & 0.032 \\
\hline S9 & 3.10 & 2.82 & 2.27 & 4.238 & 0.017 \\
\hline S10 & 4.28 & 4.26 & 3.95 & 1.288 & 0.280 \\
\hline N & 60 & 38 & 22 & 120 & \\
\hline
\end{tabular}

Based on the obtained results, we confirm $\mathrm{H} 1$ hypothesis that the respondents show interest and positive attitude towards the use of information technology to assist in the treatment of the low back pain.

\section{Discussion}

The aim of this paper was to determine how many patients use modern information and communication technology to help with acute pain. The use of digital technologies and the Internet is of great help to medical service users in their efforts to study their painful conditions and apply what they've learned in everyday life using digital information. Global Health Network Supercourse includes cooperation from 81 countries with more than 750 experts from global 
M. Berković-Šubić, G. Hofmann, B. Vuzem, Digital technology as a tool in self-management ...

health, epidemiology and the Internet and gives the reader a lot of medical information (Global Health Network Supercourse, 2016).

The results obtained in the research show an overall positive attitude of respondents to using modern digital technologies in order to help treat back pain, the sex of the respondents brings no significant difference, and the positive attitude decreases with increase in age and lower qualifications.

By applying information and communication technologies, the communication between all participants in the health care process is improved: the doctor, the physiotherapist and the patient. There are very useful freely available websites that are mostly regulated by physiotherapists from private healthcare institutions and physiotherapists' associations. Such online rehabilitation programs give the patient the assurance that they are therapeutically valid because they are recommended by a health professional from that clinical area.

Due to the long-term inaccessibility of physiotherapists in public health institutions, such form of remote consultation and patient education over the Internet improves the health care of patients in need.

In this paper, a positive attitude on the use of modern technologies (Internet, social networks) with the goal of gaining and extending knowledge on back pain is in $77.5 \%$ of respondents. The availability of advice in the form of a video or pictures of the back pain is considered useful by $85 \%$ of the respondents. Physiotherapists' guidance on the use of digital technologies for learning about the illness is considered to be useful by $79 \%$ of respondents. To the statement "I received the most information about back pain by using the Internet" $23.3 \%$ of respondents agree, which is not unusual when we look at the structure of the respondents (according to the degree of education most of the respondents belong to the group of unqualified workers $(50 \%)$ and $31.66 \%$ of respondents have a high school diploma). A positive attitude on the use of advice from biomedical databases for treating back pain is present in $35.8 \%$ of respondents.

A highly positive attitude towards using the Internet as a reminder to conduct already learned exercises for treating back pain is present in $68.3 \%$ of respondents. With the purpose of self-treating back pain $45.8 \%$ of respondents are afraid of using advice from the Internet or social media, and 33.3\% have a negative attitude about it. $25.8 \%$ respondents believe the problem lies in not knowing informational and communicational technologies in order to gain new knowledge about their condition. No knowledge of English is a problem in acquiring new knowledge about back pain in $49.1 \%$ of respondents because they have a lower level of education and older generations don't use English in everyday communication. Considering our respondents/patients suffer from back pain, which is why they are in a rehabilitation facility in the first place, their concern for gaining new information about the condition that is present in their everyday life is perfectly justified. One also can't neglect the fact that respondents with low and medium levels of education $(50 \%)$ aren't familiarized with digital technologies because their work status is tied to heavy physical work. 
Younger generations use the Internet but have given average scores because they aren't in major contact with the condition and have more faith in professionals and therapeutic procedures with professionals where they can conduct their rehabilitations in person. Older generations give lower scores because of their lower computer literacy as they have a hard time searching the Internet for information. Middle-aged respondents between the ages of 41 and 60 (59.1\%) can use computers, search the internet and use the information and knowledge gained so they have given higher scores as they already know medical information gained from the Internet is useful and reliable.

\section{Conclusion}

The rapid development of information and communication technologies has brought great benefits and advances in the ability to acquire new knowledge for healthcare users. Increased education and use of the Internet for self-treatment allows people with back pain to have an easier way of learning about their condition and using the pain relief programs offered. In this paper, the acquisition of new knowledge is rated as a high positive rating, which confirms that respondents are aware of the need for the use of modern technologies and forms of digital communication for the purpose of acquiring new knowledge and their application. The positive attitude of respondents to the use of modern technology to find useful counselling in treating back pain decreases as the age increases. The relationship of interest, expertise and attitudes about the usefulness of Internet information about back pain depends on knowledge of digital technology and foreign language (English).

\section{References}

Deyo, Richard A; Dworkin, Samuel F; Amtmann, Dagmar; Andersson, Gunnar; Borenstein, David; Carragee, Eugen; et al.. Report of the NIH Task Force on research standards for chronic low back pain. //Journal Pain. 2014;15(6):569-85

Lin, Chung-Wei Christine; Haas, Marion; Maher, Chris G; Machado, Luciana AC; van Tulder, Maurits W. Cost-effectiveness of guideline-endorsed treatments for low back pain: a systematic review. //Eur Spine J. 2011;20(7):1024-1038

American Pain Society 2007. Available at: http://annals.org/article.aspx?articleid=736814, (Accessed on 2.1.2016.)

Smith, Benjamin E; Littlewood, Chris and May, Stephen. An update of stabilization exercises for low back pain: a systematic review with meta-analysis.// BMC Musculoskelet Disord. 2014; $15: 416$

Croatian declaration on open access. Available at: http://www.uaos.unios.hr/artos/Hrvatska deklaracija_o_otvorenom_pristupu.pdf (Accessed 6. 10. 2015.)

Grazio, Simeon; Ćurković, Božidar; Vlak, Tonko; i sur. Dijagnostika i konzervativno liječenje križobolje: pregled i smjernice Hrvatskoga vertebrološkog društva. //Acta Med Croat 2012; 66: 259-94

Global Health Network Supercourse. http://www.pitt.edu/ super1/ (Accessed on 2.1. 2016.) 